\title{
DEZ ANOS DA ABRALIC (1986 - 1996): ELEMENTOS PARA SUA HISTÓRIA
}

\author{
Tania Franco Carvalhal
}

\begin{abstract}
Resumo: 1985. Antonio Candido was appointed for the Executive Committee of the International Comparative Literature Association (ICLA), during the XI Conference, in Paris. One year after the XI Congress, Porto Alegre, favoured by its geographic location, and natural bilinguism and multiculturalism, becomes the site for the Comparative Literature Brazilian Association, ABRALIC. The Latin-American participation and perspective were the central themes of the I Seminar, which was fully succesful in its proposes. Three congresses were held ever since and in August 1992, ICLA gathered together for the first time in Latin America, precisely at the Federal University of Rio Grande do Sul. The success of the Brazilian initiative is complete and the creation of several graduated courses and other institutions, similar to ABRALIC, in the neighbouring countries give evidence of that.
\end{abstract}

Palavras-chave: literatura latino-americana, Antonio Candido, literatura comparada, ABRALIC, Associação Internacional de Literatura Comparada.

\section{NARRATIVA DE UM COMEÇO}

No verão europeu de 1985, Paris sediava o XI Congresso da Associação Internacional de Literatura Comparada. As salas da antiga Sorbonne eram escassas para o expressivo número de participantes. Nelas circulavam comparatistas vindos de todos os lugares e era possível encontrar nos corredores Etiemble e René Wellek , Henry H. H. Remak e Eva Kushner, Ulrich Weisstein e Pierre Brunel entre figuras que constituem a própria história do comparatismo. Para os jovens comparatistas e, particularmente, para aqueles oriundos de países jovens como o Brasil, a participação no Congresso da AILC/ICLA significava integrar-se em um universo cosmopolita no qual se cruzavam diversas línguas e muitas orientações divergentes. Paris era a sede ideal para a evocação de todo o percurso de uma disciplina que ali mesmo começara, no início do século. Um bom lugar para

Universidade Federal do Rio Grande do Sul 
(re)descobertas e grandes decisões. Afinal fora ali, na Place Clichy, umbigo do mundo, que Oswald de Andrade redescobrira o Brasil, conforme nos conta Paulo Prado no Prefácio à Poesia Pau-Brasil, de 1924.

Naquele agosto de 1985, na Place de la Sorbonne, entusiasmados com a eleição de Antonio Candido para o Comitê Executivo da AILC (embora não estando ele presente no Congresso) vindo a ser o primeiro latino-americano a integrá-lo, os brasileiros presentes decidiram fundar uma Associação de Comparatistas em seu país ${ }^{1}$.

A sede da nova Associação seria Brasília, por sua localização central. Mas no retorno ao Brasil, por diversas injunções, o planejamento inicial não se concretizou e Porto Alegre acabou sendo identificada como a cidade que teria condições para essa fundação. Assim, a Associação Brasileira de Literatura Comparada (a ABRALIC), surge em 1986, no âmbito do I Seminário Latino-americano de Literatura Comparada, realizado de 8 a 10 de setembro na Universidade Federal do Rio Grande do Sul, com a participação de alguns comparatistas europeus, mas sobretudo de estudiosos latino-americanos.

A ênfase no contexto latino-americano era estratégica. Situados em um Estado de fronteira, vizinho ao Uruguai e à Argentina, os estudiosos de Porto Alegre tinham uma intenção clara, isto é, a de estimular a integração latino-americana e a de explorar as diferenças lingüísticas e culturais existentes nos países do continente. O bilingüísmo e o multiculturalismo já eram ali mesmo uma premissa natural, favorecendo o surgimento de estudos comparados. Além disso, consolidado que estava o hábito de confrontar a literatura brasileira com as européias, faltava no Brasil multiplicar os campos de atuação comparatista em novos contextos, pois isso permitiria a construção de um novo objeto e a conseqüiente redefinição da própria disciplina. Esse novo campo preferencial de atuação da literatura comparada seria o das literaturas do continente latino-americano, culturalmente plural e, por isso mesmo, próprio à prática comparatista.

A imagem reproduzida no cartaz, nos folders e, depois, nos volumes dos Anais era expressiva: o fragmento da cena canibalesca, que emoldura a reedição fac-similada da Revista de Antropofagia (1976) em suas duas fases 1928/1929 (dentições), buscava recriar o espírito de utopia que imantava a publicação e o movimento e, sobretudo, chamar a atenção para o procedimento de assimilação que neles eram implícitos. Tomava-se a Antropofagia como emblema, porque, no dizer de Augusto de Campos (no prefácio à referida reedição), é "a única filosofia original brasileira e, sob alguns aspectos, o mais radical dos movimentos artísticos que produzimos" e porque se tratava de uma crítica radical da cultura brasileira no melhor estilo parodístico. Na observação de Benedito Nunes (citada no prefácio),

\footnotetext{
${ }^{1}$ Participaram do XI Congresso da AILC Eduardo Faria Coutinho, Idelette Muzart Fonseca dos Santos, Neide de Faria e Tania Franco Carvalhal. Esse mesmo grupo, acrescido de Antonio Manoel dos Santos Silva, já havia projetado a Associação em reunião de coordenadores de PósGraduação, na CAPES-MEC, Brasília, em 1984.
} 
"a imagem oswaldiana do antropófago e o conceito respectivo de assimilação subordinam-se, portanto, a uma forma de concepção que os vários canibalismos literários da época reunidos não podem preencher" (CAMPOS, 1976). Ainda o mesmo crítico, em outro lugar, na análise da palavra antropofagia "como pedra de escândalo, para ferir a imaginação do leitor com a lembrança desagradável do canibalismo, transformada em possibilidade permanente da espécie", dirá que se trata de "um vocábulo catalizador, reativo e elástico, que mobiliza negações numa só negação, de que a prática do canibalismo, a devoração antropofágica, é o símbolo cruento" (NUNES, 1970). O I Semário tomou a Antropofagia justamente nessa acepção, a da devoração criadora, que, através de uma assimilação seletiva, conduz à elaboração do novo e do próprio.

Indo ao texto do próprio Manifesto, encontrava-se em alguns dos seus aforismos a inspiração necessária para uma prática comparatista renovada: "Só me interessa o que não é meu. Lei do homem. Lei do antropófago". Mais adiante: "Contra todos os importadores de consciência enlatada". Ou ainda: "Sem nós, a Europa não teria siquer a sua pobre declaração dos direitos do homem. A edade de ouro annunciada pela America". Para completar, entre outras intuições vistas como instigantes: "Contra a Memoria fonte do costume. A experiência pessoal renovada". Algumas dessas citações embasaram o projeto do I Seminário, cujo temário básico previu três grandes linhas: as relações culturais da América Latina com os contextos europeu e africano, as inter-relações culturais na América Latina e, finalmente, perspectivas comparatistas nas literaturas latino-americanas. Como se percebe, por essa tríade temática, procurava-se multiplicar os campos de indagação e, simultaneamente, enfatizar o estudo das relações internas das literaturas do continente. Por fim, pretendia-se expor, em toda sua amplitude e divergência de orientações, o comparatismo praticado na América Latina. Por isso, o objetivo central do I Seminário era que o encontro de pesquisadores latino-americanos permitisse articular linhas de investigação comuns que possibilitassem pensar a América Latina através de suas manifestações culturais visando ao conhecimento do que lhe é próprio e, sobretudo, à sua integração continental. Um simples olhar para a programação desenvolvida no I Seminário ilustra os resultados obtidos. Enquanto Ana Pizarro examinou El discurso literário y la noción de América Latina, Josefina Ludmer expôs sobre La literatura gauchesca y el nacionalismo, Jorge Schwartz tratou de La crítica de la vanguardia latinoamericana e Haroldo de Campos ilustrou magistralmente sua teoria da tradução em Transblanco: reflexões sobre a tradução de Blanco de Octavio $\mathrm{Paz}$. Outras questões teóricas essenciais ao comparatismo foram ainda examinadas: Boris Schnaiderman ocupou-se com Tradução: fidelidade filológica e fidelidade estilística, Ivan Junqueira refletiu sobre Eliot $e$ Baudelaire: Tradução e Traição e Beatriz Sarlo sobre Orígenes de la ficción. Se essas breves referências apontam para o interesse das exposições, elas indicam também que os temas não foram só pontuais, mas alguns tinham 
caráter amplo. A leitura dos textos encaminhados antes do evento nos fez perceber logo o seu significado e importância. Por isso, decidimos editar os textos das comunicações já enviadas para que, ao chegar, os participantes tivessem acesso imediato e direto aos conteúdos selecionados, e pudessem discutir, de maneira rentável, o que ali se estava a expor. Esse foi mais um aspecto positivo do I Seminário .

Para sua organização, foi decisiva a acolhida dada em todo o país e nos países vizinhos ao projeto, como também o apoio recebido da UFRGS e de órgãos de fomento à Pesquisa e à Formação de Recursos Humanos como o CNPq, a CAPES, a FINEP e a FAPERGS. Graças aos auxílios obtidos, à representatividade intelectual dos participantes e ao valor das comunicações, Porto Alegre converteu-se, por três dias, em um centro cultural que reproduziu, no ânimo comparatista, mesmo com suas precárias e provincianas dimensões, a Paris do ano anterior.

Como explicar o êxito da iniciativa? Pode-se dizer que o I Seminário veio ao encontro de uma demanda reprimida, para usarmos um termo do mercado de produção. Isso porque em toda a América Latina (e não só no Brasil) praticava-se largamente o comparatismo, como forma natural de contrastar uma literatura nova com aquelas já consolidadas e de onde é oriunda. No Brasil, embora só houvesse programas de pós-graduação em literatura comparada nas Universidades de São Paulo e do Rio de Janeiro até aquele momento, estudos comparatistas também se realizavam em vários pontos do país. No entanto, havia um desconhecimento generalizado do comparatismo que se praticava efetivamente em cada lugar. Havia, também, uma carência de sistematização no que tange, sobretudo, a metodologias e posições teóricas. O I Seminário propiciou, então, uma visão global que nos permitia traçar um panorama mais claro da literatura comparada no país e mesmo no continente. Acrescente-se a isso o fato de que a comparação é recurso crítico indispensável à reflexão sobre a literatura continental como totalidade e, ao proporcionar o confronto das literaturas latino-americanas entre si, o I Seminário apontava para a construção de um novo objeto teórico constituído das diversas literaturas nacionais do continente.

\section{A CONSOLIDAÇÃO}

Dois anos depois, ainda em Porto Alegre, Antonio Candido, como Homenageado do I Congresso da plenamente constituída ABRALIC, viria a definir de forma exemplar o sentido da criação de uma Associação comparatista no Brasil, ao dizer que esta era uma "entidade que representa uma fase nova da disciplina em nosso meio". Segundo ele, "a organização associativa dos especialistas é sinal de maturidade, e com certeza ajudará a Literatura Comparada brasileira a entrar na era do funcionamento sistemático". E completa, mais adiante: "Penso que a Associação Brasileira de Literatura Comparada, ABRALIC, encerra o período que começou pelas manifestações espontâneas, passou mais tarde à prática individualizada, antes 
de alcançar o reconhecimento institucional.” Após detalhar esse percurso, suas palavras finais tinham um caráter profético e vale a pena transcrevê-las. Ali, diz Antonio Candido: "Mas faltava algo importante, e eu diria decisivo: a consciência profissional específica, que se adquire e fortalece sobretudo pelo intercâmbio, os periódicos especializados e a vida associativa, marcada por encontros, simpósios e congressos. Foi o que começou com a ABRALIC. Por isso penso que esta corresponde a uma certidão de maioridade da Literatura Comparada no Brasil" (CANDIDO, 1988). Os anos seguintes viriam confirmar amplamente essas afirmações.

Com efeito, o primeiro Congresso, também realizado na Universidade Federal do Rio Grande do Sul, no período de 1 a 4 de junho de 1988, sob a presidência de Tania Franco Carvalhal, comprovou a maturidade dos comparatistas brasileiros pelo aprofundamento em questões específicas da disciplina, pela densidade dos trabalhos apresentados e no conhecimento por eles demonstrado do que se praticava universalmente como literatura comparada.

Os temas desse primeiro Congresso - Intertextualidade $e$ Interdisciplinaridade - estimularam estudos os mais variados, desde análises localizadas de obras a questões de natureza teórica. Três volumes publicados no ano seguinte dão a dimensão exata do alcance e da importância das reflexões ali difundidas. A participação, mais uma vez, de especialistas estrangeiros como Maria Alzira Seixo, Douwe Fokkema, Vitor Manuel de Aguiar e Silva, Henry H. H. Remak, Pierre Brunel, Ana Pizarro, Duarte Mimoso-Ruiz, Jean Marie Grassin, Lisa Block de Behar, Riccardo Campa, Maximilien Laroche, John Gledson, Salvato Trigo, George Yúdice, Walter Moser, entre outros, ao lado dos brasileiros Antonio Candido (homenageado de honra), Boris Schnaiderman, Haroldo de Campos, João Alexandre Barbosa, Silviano Santiago, Wilton Cardoso, Davi Arrigucci Júnior, Luiz Costa Lima, Ana Lúcia Gazolla, Eneida M. de Souza, Eduardo F. Coutinho, Flora Sussekind, para citar apenas alguns entre inúmeros outros, permitiu uma riquíssima troca de idéias e de experiências. Com a participação de comparatistas portugueses, franceses, norte-americanos, alemães, italianos, canadenses, belgas e espanhóis, a ABRALIC firmava, já neste Primeiro Congresso, os laços que iniciara a estabelecer em 1985 com a AILC, tornando o Brasil um ponto de referência obrigatório na cartografia comparatista. Impressionados com a vitalidade da investigação de natureza comparatista em nosso país, começaram a demonstrar um interesse renovado na participação em eventos nacionais. Por isso, alguns dos nomes mencionados acima e outros mais vieram integrar as atividades do Segundo Congresso da ABRALIC, realizado em Belo Horizonte, em 8 a 10 de agosto de 1990, em torno ao tema Literatura e Memória Cultural. A publicação dos Anais, em três volumes, veio comprovar a alta qualidade das apresentações, distribuídas em sessões plenárias, mesas-redondas e comunicações, como também a multiplicidade de perspectivas que o temário permitiu desenvolver. $\mathrm{Na}$ abertura do primeiro volume, a $2^{\mathrm{a}}$ Presidente da ABRALIC, Eneida Maria 
de Souza, salienta "que não resta a menor dúvida de que a literatura comparada no Brasil vem atingindo posição de destaque no meio acadêmico, pela efetiva vitalidade da Associação, que não se furta em proporcionar à comunidade o constante fórum de debates". Coube, ainda, à segunda Diretoria da ABRALIC, transformar o Boletim inicial, intitulado Contraponto, em uma Revista, cujo primeiro número registra contribuições importantes e conta hoje com dois números editados. Estava, em definitivo, estabelecido o futuro da Associação Brasileira de Literatura Comparada, que acolheu, desde o início, comparatistas de profissão, mas também especialistas de literatura nacional e de literaturas estrangeiras em cujos trabalhos se pode identificar uma inclinação comparatista. Nesse sentido, a ABRALIC acabou se convertendo na Associação de estudiosos de literatura numericamente mais expressiva no país. O Terceiro Congresso, realizado de 10 a 12 de agosto de 1992, em Niterói, sediado na Universidade Federal Fluminense, sob a presidência de Silviano Santiago, escolheu como temática a noção de Limites. Como se observa na Nota Prévia ao primeiro dos dois alentados volumes dos Anais, "na produção teórica e analítica dos companheiros de letras, estão temas que caminham tanto para a interdisciplinaridade quanto para a intertextualidade, e ainda para uma possível intercomunicação entre os vários discursos artísticos". Proporcionava-se assim que se discutissem de forma generalizada questões fronteiras em sentido amplo, na medida em que a ultrapassagem de limites é central para a atuação comparatista. A terceira Diretoria da ABRALIC organizou ainda três Congressos de pequeno porte no ano ímpar de sua gestão, contribuindo dessa forma para a consolidação dos estudos de literatura comparada no país. Um deles, realizado em Florianópolis e sob a organização de Raúl Antelo, resultou no volume Identidade Representação,

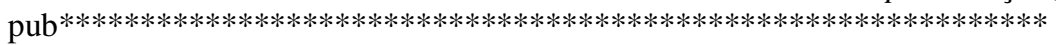

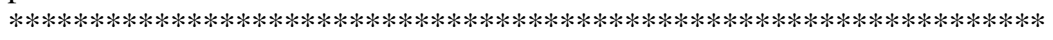
********************************************************************** *********************************************************************** **********************************************************************

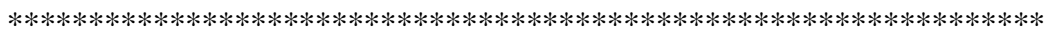

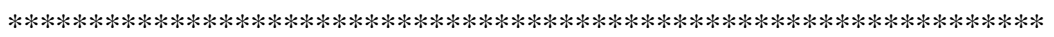
*************************************************************************** $* * *$ o da literatura comparada no continente.

O Quarto Congresso da ABRALIC ocorreu na Universidade de São Paulo, de 31 de julho a 3 de agosto de 1994, sob a presidência de Benjamin Abdalla Júnior, tomando por tema Literatura e Diferença. Com a apresentação de 432 comunicações, esse Congresso registrou também um excelente nível científico. Como consta da Apresentação do alentado volume dos Anais já editado, a ocasião "mostrou-se forma eficaz para a veiculação e discussão de questões teóricas e críticas da literatura comparada, com contribuições importantes para os estudos literários no país." Ressalta-se, no conjunto das exposições, "trabalhos em que a circulação literária foi 
pesquisada e estudada com ênfase no descentramento de óptica, de forma a se analisar, com os pés na periferia, as imbricações entre o regional e o nacional, entre o nacional e o supranacional e entre a série literária e as demais séries culturais." Essa publicação veio enriquecer a bibliografia existente na área.

Desse modo, os Anais dos quatro primeiros Congressos, os três números iniciais do Boletim Contraponto, os dois números da Revista da Abralic já constituem uma bibliografia básica e representativa do comparatismo no Brasil, documentação útil à pesquisa de sua evolução e para a consulta pontual sobre métodos e fundamentos teóricos.

\section{EM DIREÇÃO AO NOVO MILÊNIO}

Os fatos relatados até aqui apontam para as perspectivas de um fortalecimento constante no campo dos estudos comparatistas entre nós. Essa consolidação se expressou, também, por uma mais rápida institucionalização desses estudos. As Universidades Federais de Minas Gerais (UFMG) e do Rio Grande do Sul (UFRGS) contam com programas de Doutorado em Letras - Literatura Comparada, com várias teses defendidas na área, o que reforça substancialmente a massa crítica docente dos programas. Há, igualmente, vários mestrados em Literatura Comparada no país, como na Universidade Federal do Rio Grande do Norte, em Natal, e cursos de especialização como em Rio Branco, no estado do Acre, para ficarmos em apenas dois exemplos. Eles já nos dizem que estamos longe da observação de Guilhermino Cesar, inserida em artigo de jornal sobre Metastásio, quando lamenta que

\footnotetext{
"os estudos de literatura comparada são pobres e raros, neste país. Principalmente nas universidades. O espírito que animou Arturo Farinelli, ou Carolina Michaelis, ou Ernst Robert Curtius não baixou ainda em nosso terreiro. Continuamos mais ligados à frivolidade do boulevard" (CESAR, 1978).
}

Naquela ocasião, o crítico ressaltava que

"há muita matéria digna de melhor exame em nossa literatura
ainda jovem, mas tão criadora. O citado Metastásio, por exemplo,
pode ser incluído no rol dos autores a quem o Brasil precisa dar
uma atenção crítica mais generosa e vigilante, já que no passado
nós o copiamos, deformamos, lemos e treslemos, divulgamos e
desrespeitamos. A obra dos árcades, mineiros e outros, documenta
de modo insofismável a marca indelével por ele deixada nos
processos, recursos e temas em voga no século XVIII. E ainda no
seguinte, pois a obra de Cláudio, que entra pelo século XIX
adentro, e a de Silva Alvarenga, ainda de modo tão inequívoco, 
acusam muitas pegadas do discípulo de Gravaina" (CESAR, $1978)^{2}$.

A transcrição dessa passagem ilustra exemplarmente todo um programa de estudos comparatistas no qual não apenas a identificação de fontes seria buscada mas, acima dela, estaria a análise dos modos de apropriação e dos efeitos das sugestões de Metastásio nos poetas brasileiros. Copiar, deformar, ler, tresler, divulgar, desrespeitar são procedimentos que, segundo o crítico, pedem investigação. Guilhermino Cesar antecipava, assim, muito das orientações atuais em literatura comparada e apontava para a pertinência e a carência desse tipo de investigação literária no campo da literatura brasileira.

Mas além da ampliação desse tipo de estudo no país, é preciso considerar que, sob o estímulo da criação da ABRALIC, entidades similares se constituíram nos países vizinhos. Em 1989, no âmbito do II Seminário Latino-Americano de Literatura Comparada, realizado em Montevidéu, com organização de Lisa Block de Behar, fundou-se a Agrupación Uruguaya de Literatura Comparada, a AULICO. O II Seminário foi registrado na publicação Terminos de Comparacion: Los Estudios Literarios entre Historias y Teorias, coordenada por Lisa Block de Behar e editada em 1991 pela Academia Nacional de Letras do Uruguay. Em 1990, em Buenos Aires, foi fundada a AALC, Associación Argentina de Literatura Comparada, no âmbito das Primeras Jornadas Nacionales de Literatura Comparada. Sob a presidência de Nicolás Dornheim realizaram-se, em 1992, as Segundas Jornadas da entidade, na Universidade de Cuyo, em Mendoza. As Terceras Jornadas, com o tema Literatura e identidad Latinoamericana, ocorrerão de 22 a 24 de agosto de 1996, na cidade de Córdoba, sob a presidência de Pierina Lidia Moreau. Também no México há sinais de um movimento associativo.

A ABRALIC, por sua vez, sob a presidência de Eduardo de Faria Coutinho, da Universidade Federal do Rio de Janeiro, organizou seu Quinto Congresso ocorrido no período de 31 de julho a 3 de agosto de 1996 naquela cidade, tomando como tema geral Cânones e Contextos. Tendo já editado um número do Boletim Contraponto, a atual Diretoria prepara também um terceiro número da Revista da ABRALIC.

Como se percebe, as atividades de congraçamento e de intercâmbio de estudiosos, de trocas de informações e de experiências, têm procurado manter o seu registro. As publicações resultantes são os documentos que poderão, no futuro, contar a história integral da evolução de correntes e do desenvolvimento de modos e meios de atuação no campo dos estudos comparatistas no Brasil. Tendo-se convertido em um fator de reunião de

\footnotetext{
${ }^{2}$ A identificação deste texto deve-se à pesquisa "Cadernos de Sábado: leituras críticas", que desenvolvo com o apoio do CNPq.
} 
especialistas com várias perspectivas teóricas, que legitimam a prática comparatista, a entidade associativa colabora também para o registro dessa variedade. Assim, as publicações da ABRALIC, como catalizadoras de estudos de literaturas, possibilitam o conhecimento e a análise de todo um decênio de pesquisa comparatista no país.

Com a aproximação do novo milênio, que instaura uma fase de instabilidade natural a toda transição, e a globalização atual, que redimensiona o nosso entendimento do Outro, o comparatismo tende a ser cada vez mais rentável e eficaz. O interesse pelo contraste, a necessidade permanente do confronto como recurso necessário ao entendimento do alheio explicam a ênfase dada à perspectiva comparatista nos mais variados campos de estudo. Sua imbricação nos diferentes territórios do conhecimento nos diz que, entre nós, a literatura comparada consolidou-se integralmente. É possível que no novo milênio esses estudos nos possibilitem contribuir efetivamente para a alteração dos paradigmas vigentes, neles introduzindo traços de um comparatismo latino-americano, ancorado no multiculturalismo que caracteriza o continente.

\section{BIBLIOGRAFIA}

CAMPOS, Augusto de. Revistas re-vistas: os antropófagos. Revista de Antropofagia (reedição), São Paulo, $1^{\mathrm{a}}$ e $2^{\mathrm{a}}$ Dentições - 1928-1929. São Paulo, Metal Leve S.A., 1976.

CANDIDO, Antonio. In: Anais do $1^{\circ}$ Congresso da ABRALIC. Porto Alegre, UFRGS, v. I, 1988.

CESAR, Guilhermino. Metastásio em dois tempos. Cadernos de Sábado. Suplemento Literário do Correio do Povo, Porto Alegre, p.3, 18.02.1978.

PRADO, Paulo. Prefácio à poesia Pau-Brasil. In: ANDRADE, Oswald de. Poesias Reunidas. São Paulo, Difusão Européia do Livro, 1966. 